\title{
Paul Crowther
}

\section{Art, Knowledge and Historicity}

\section{Introduction}

William Elton's influential volume Aesthetics and Language (1954) included a paper by John Passmore entitled 'The Dreariness of Aesthetics'. This - and the other contributions to the volume - represented the first major wave of Wittgenstein-inspired reaction against twentieth-century romantic and idealist aesthetics. Scorn was poured on descriptions of subjective experience, cosy affirmations of 'spiritual' truth and any notions of essentialism. Emphasis instead, was placed on the investigation of how aesthetic and critical terms are actually used in the languages of art discourse.

In time this view was modified, at least in the context of the definition of art. With the rise of Institutional-type approaches, it was now allowed that art could be defined, albeit not in terms of common essential properties at the objective level. Rather the features which defined art were seen to lie in the underlying context of social praxis or language-games. The most that could be allowed to art qua perceptible object was that, in some sense or other, it was an artifact. Even this claim, however, became the subject of controversy.

At the same time, developments in the field of art itself - such as 'neo-Dada', and, more notably, the rise of minimalism and conceptual art, also seemed to raise questions about whether art could be defined in terms of any notion of objecthood. 
The upshot all these tendencies is that, in the tradition of analytic philosophy at least, aesthetics has become something of a dreary discipline again. Art is seen as, in effect, as anything an artist chooses to call art. The philosophical debate addresses a few tangential issues of just where the boundaries of art can exactly be drawn, rather than question such as why art is of recurrent significance in human life.

Of course, it hasn't all been bad news. Nelson Goodman's Languages of Art (1968) and, to lesser extent Richard Wollheim's Art and Its Objects (1968) shifted attention to issues of art's symbolic structures, and, since then, much really valuable work has been done on such questions as pictorial representation, the nature of fictional discourse, and meaning in music. Unfortunately, this semantic approach has also shown some severe limitations. The most notable of these consists in that whilst artworks are symbolic formations, it is not the symbolic structures of a medium per se, which enable that medium to function as art. To put this another way, not all forms of, say, pictorial representation or fiction are art; and what has been lacking is an adequate explanation of under what conditions such symbolic formations do count as artworks.

More recently, the whole question of art, its structures and definitions, has been given a radical reinterpretation by proponents of the various strands of poststructuralism. What is at issue here, is not what makes something art, but the various power relations based on class, race, and gender, which specific artworks (and, indeed disciplines such as aesthetics itself) embody and reinforce. Again, however, much is lost in such approaches. In particular, by reducing art and the aesthetics to the preferences of dominant power-groups no justice is done to the potentially universal and liberating functions of art.

My grumble, then, is that in the post-war period aesthetics as a discipline has become distorted. The analytic tradition has either trivialised the concept of art or focused too closely on its semantic superstructures; whilst the more radical poststructuralist approaches have reduced it, in effect, to the ideology of group preferences. Somewhere between these extremes, however, art has survived - albeit misunderstood. 
Given this, what is needed is an analysis of art in relation to self-consciousness itself. Such a view would develop an ontology of art in relation to an ontology of the human condition. The groundwork for such an investigation has been in place for a long time. In the nineteenth-century, for example, there is some continuity between the aesthetic theories of Kant, Schiller, Hegel, and Schopenhauer. All see art as a vehicle for aesthetic ideas i.e. as a distinctive form of knowledge wherein the conceptual or symbolic dimension is inseparably bonded to a sensible or imaginative foundation. More than this, indeed, art is seen as having an essential relation to self-consciousness. The different thinkers mentioned interpret this relation in different ways; but ail agree that in the experience of art, self-consciousness is 'at home' or in some sense reconciled with existence. It knows itself with a fullness and depth which is not available in most modes of intercourse with the world.

In the twentieth-century this approach has persisted - at least in the traditions of existential and hermeneutic philosophy. Through being appropriated by these traditions the theory has shed some of its more unacceptable baggage of philosophical idealism. However, it is still tied very closely to the particular thinkers who utilise it (e.g. Heidegger, Gadamer, and Merleau-Ponty) and requires, therefore, further refinement in order to bring out its full potential.

I have begun this task in my books Critical Aesthetics and Postmodernism and Art and Embodiment. Rather than simply restate the position arrived at in those works, I shall adopt the following strategy. In the remainder of this chapter, I shall embody the techniques of analytic philosophy in a critique of what I shall call designation theories of art. The idea that art can be created by an artist simply designating something as art (rather than by making it) lies at the heart of the various institutional definitions of art. Interestingly, something like this is also implied in poststructuralist approaches, if they are to be of anything other than merely negative import. The reason for this is as follows. Traditional definitions of art reflect the logocentric prejudices of white male middle-class heterosexual patriarchy. If, therefore, art is to be liberated from such prejudices, it must be defined in terms of new sets of relations which reflect the diversity of interests present in a society. The 
only definition which will accommodate such diversity, is one which sees art as a set of heterogeneous practices capable of complete transformation in terms of their scope and content, as societal conditions change. This means that choice and acts of designation, rather than the possession of epistemologically 'closed' sets of properties must be paramount.

Clearly, then, a refutation of the designation theory will have ramifications beyond a critique of analytic philosophy pure and simple. Having offered such a refutation, I will then present my substantive theory in a Chapter entitled 'Art as a Form of Knowledge'. The means adopted will be an exposition, critical interpretation, and development of some ideas from Gadamer. In the course of this, I will clarify some of the ways in which art reflects essential structures of experience, and something of its relation to kitsch, and to non-artistic modes of signification.

\section{I: DESIGNATION THEORIES OF ART: A CRITIQUE}

The significance of the institutional aspect of art was first made manifest by Duchamp's creation of 'readymades. It was not, however, until Arthur Danto's paper 'The Artworld', that its philosophical relevance became apparent. I shall therefore commence my critique with a detailed consideration of Danto's position.

Let us begin with the strange case of the 'is' of artistic identification, 2 a sense of 'is' which Danto claims to be wholly apart from its usual role in statements of existence, identity, and predication. In respect of it, we are given the example of the "10th Street Abstractionist' who says of his work that 'That black paint is black paint'.

\footnotetext{
1 I am indebted to my colleague Dr Christina Lodder for discussing the first draft of this section with me.

2 Arthur Danto 'The Artworld', Journal of Philosophy, LXI, 1964. Included in Aesthetics: A Critical Anthology ed. George Dicke and Richard Sclafani, (New York: St. Martin's Press, 1977) pp. 22-35. For the purpose of this study, page references to Danto's papers will be based on those included in the Dickie/Sclafani anthology, unless stated otherwise.
} 
Now here, according to Danto, the artist is not simply uttering a tautology, but is using 'is' in its unique artistic sense. His statement means more than it ostensibly says because he has

... returned to the physicality of paint through an atmosphere compounded of artistic theories and the history of recent and remote painting, elements of which he is trying to refine out of his own work; and as a consequence of this his work belongs in this atmosphere and is part of this theory.

Bearing these points in mind, let us consider another of Danto's examples of this 'is' of artistic identification. We look at a painting and say 'that white dab is Icarus'. Now if we were using 'is' here, in the normal sense of identification, we would face a contradiction, since, with equal justice, the contrary statement could also be affirmed. The point is, that viewed as part of an artwork, the white dab 'is' Icarus; but viewed as a part of the real world, the white dab is just a white dab of paint. Interestingly, Danto refuses to admit the possibility that in, say, 'That dab is Icarus' we are simply saying that the dab 'stands for' or 'represents' Icarus. His reason for this, is that

... the word "Icarus" stands for or represents Icarus; yet I would not in the same sense of "is" point to the word and say that is Icarus. ${ }^{1}$

It is unfortunate that Danto uses this example, because it raises some questions which can lead to us missing both his substantial point of argument and its weaknesses. William Kennick ${ }^{2}$ for example, has retorted that the word 'Icarus' means Icarus, but that the dab of paint doesn't. On these terms we are quite justified in saying that the dab of paint is a representation of Icarus, but that the word is not. Kennick then takes this point to some interesting conclusions. First, he claims that Danto is using a hybrid sense of 'is' which involves both the ordinary sense of identification, and that sense of 'is' which is used specifically in predicating representational qualities. This, according to Kennick, leads to a difficulty, because Danto claims that the 'is' of artistic identification has necessary application to both representational and abstract works.

1 Ibid., p. 27.

2 William Kennick, 'Theories of Art and the Artworld', Journal of Philosophy, LXI (1964), pp. 585-587. 
There are, however, a number of things to say about Kennick's remarks. The most important is that in allowing even a 'hybrid' sense to the 'is' of artistic identification, he is allowing Danto too much. For example, it is clear that in the case noted above, Danto is pointing out that whilst words have a referential sense, pictures have this and much more besides. But in what does this 'much more' consist? Simply, (one would have thought) in the fact that pictorial representation achieves its referential sense at least partially by virtue of iconicity i.e. through the fact that, say, a picture of Icarus (or a picture with him 'in' it) 'looks like', or contains an 'image of' a winged human figure. This image, in conjunction with the work's title or our knowledge of Greek myth, leads us to take the image as being 'of' Icarus. Hence, when we say that 'That white dab is Icarus' we are, in effect, giving an abbreviated description, which, analysed, would come out as something like 'That white dab is an image used to stand for Icarus'. In such a case, therefore, we are not using a special sense of 'is' but the customary one of predication - the same sense in fact, as we would use in saying 'That word is /stands for/ Icarus'. The point to gather from this, is that whilst statements about how words refer, may have a different 'sense' from statements about how picture refer, the difference is due not to any unique or hybrid kind of 'is', but to a contrasting complexity in the predicate involved.

What Danto is really talking about, then, is not an 'is' of artistic identification, but the fact that in talking about artworks some of our predicates have a complex sense which is only intelligible in the context of art theory and practice. I shall call these 'art-predicates'. We are now in a position to understand why Kennick rather misses Danto's point in relation to representational properties. Danto is not, in fact, saying that all artworks are representational, but that they have emergent properties (of either a representational, or more loosely referential sort) which can only be recognised by someone who is familiar with the theory and practice of art. For example, in order for us to say 'That dab is Icarus', we must have grasped some fundamentals of artistic practice specifically the convention whereby marks on a canvas are to be recognised as being 'of' such and such a subject-matter; in this case, Icarus. Similarly, to grasp the full signification of the predicate in the 10th Street Abstractionist's claim that 'That black paint is black paint' we 
must be familiar with the art theory and history which has led him to produce such a work. It is by reference to these, that we see what the work is 'about'.

We find, then, that, demystified, Danto's 'is' of artistic identification turns out to be a quite reasonable claim about the nature of art-predicates. However, the real substance of Danto's argument emerges only when he moves beyond this initial characterisation. We are told, for example, that a mastery of the 'is' of artistic identification actually, (to use Danto's own term) 'constitutes' works of art. Put in demystified terms, this amounts to a claim that the application of art-predicates enables not only the recognition of an artwork, but also, in certain circumstances, confers the status 'work of art' upon that otherwise would only be a real thing. Now it might seem that Danto is simply proposing a rather Berkeleyian point here. Mona Lisa (or any other painting) for example, is simply a number of marks upon a canvas - a mere real thing until an initiate of the artworld perceives them and in so doing constitutes them 'as' a representation of the exquisite lady. There is something of this in Danto's theory, but it overlays an even more fundamental point - namely that art-predicates can even apply to objects which have not been physically created by artists. Danto gives the following example.

Testamorbida is a playwright who deals in Found Drama... he declares his latest play to have been everything that happened in life of a family in Astoria between last Saturday and tonight. ${ }^{1}$

We must not be deceived by the lighthearted tone of this example. Danto seriously holds that what are otherwise pre-eminently real things - such as bottleracks, events in Astoria, or copies of the 1978 Manhattan telephone directory, can be genuine works of art. All that is required is for an artist to actually declare as much - either verbally, or by simply placing the object in an art gallery. By this act of designation, the object is moved into the realm of art-history and theory, and thus becomes a potential subject for statements containing art-predicates. This approach, of course, places the determining ground of art firmly in the

1 Arthur Danto, 'Artworks and Real Things', Theoria, XLIX (1973). Included in Dickie and Sclafani, op. cit., pp. 551-562. This reference, p. 558. 
realm of the artist's conceptions, rather than in his making of artifacts of a specific kind. I shall hereafter term this the Designation theory of art.

What is quite extraordinary, is the huge influence which this theory has had. It is found, for example, in various guises and degrees of hardness and softness, in the work of Timothy Binkley, ${ }^{1}$ George Dickie, ${ }^{2}$ Gene Blocker, ${ }^{3}$ Jerrold Levinson, ${ }^{4}$ Jack Glickman,, Joseph Margolis, ${ }^{6}$ and, more surprisingly, Nelson Goodman. ${ }^{7}$ Indeed the very title of Goodman's paper 'When is Art' makes play on there being, as it were, a 'decisive moment' when some object comes to exist as an artwork through being designated as such.

Now of all these aestheticians, it is Binkley who pushes the hardest version of the Designation theory. For him, anyone (in principle) can be an artist, and anything (in principle) can be designated as art. Most of the theory's proponents, however, would probably follow Danto in his claim that there are two conditions which must be fulfilled in order for an item to be designated work of art. ${ }^{8}$ First, the designated work must not be a fake or a copy; and second, it must have been designated by someone who is, or was, an artist. To really get the argument off the ground, we must add, I think, two further conditions. First, in designating some object as an artwork, the artist must be honest in his or her designation i.e. not simply trying to pull the wool over the public's eyes. Second, (a related point) the designation should be carried

1 See for example, Timothy Binkley, 'Piece: Contra Aesthetics', Journal of Aesthetics and Art Criticism, XXXV, (1977), pp. 256-277.

2 See especially, George Dickie, Art and the Aesthetics (London: Cornell University Press, 1974), chapter One.

3 For example, H. Gene Blocker, 'Autonomy, Reference, and Post-Modern Art', British Journal of Aesthetics, Vol. 20, No. 3 (1980), pp. 229-236.

4 For example, Jerrold Levinson, 'Defining Art Historically' British Journal of Aesthetics, Vol. 19, No. 3, (1979), pp. 233-250.

5 For example, Jack Glickman, 'Creativity in the Arts', included in the second edition of Philosophy Looks at the Arts, ed. Joseph Margolis, (Philadelphia: Temple University Press, 1978) pp. 145-162.

6 See especially, Joseph Margolis, Art and Philosophy (Hassocks: Harvester Press, 1980), Chapter Three.

7 Nelson Goodman, 'When is art', included in his Ways of Worldmaking (Hassocks: Harvester Press, 1978) pp. 57-70.

8 See 'Artworks and Real Things' included in Dickie and Sclafani, op. cit., 559-561. 
out on the basis of some rational theory about the possibilities of art. This would disqualify objects designated by mere caprice, or in moments of insanity. (In the latter case, however, it would always be open for an artist to redesignate the object as an artwork or regaining his or her senses.)

Taking these conditions into account, it is possible to give a fuller statement of the Designation theory in a way that would broadly fit all its proponents. If ' $x$ ' is designated 'artwork' by an artist acting on the basis of some rational theory about art; then, art being what it is (unlimitedly creative etc) ' $\mathrm{x}$ ' is an artwork. This formulation at least makes clear that the Designation theory is not saying artworks are created arbitrarily, but it does so at the price of reducing philosophical aesthetics (for reasons which will become apparent) to a kind of speculative art-theology. Now one superficially very promising objection to the theory is that is seems unable to accommodate what might be called 'paradigm conflicts' within the artworld. For example, if two artists hold entirely different theories as to what counts as art, we might expect that the classes of objects they designate as artworks will be mutually incompatible. Yet, on the basis of the Designation theory, we must allow that both artists are right. This apparent paradox van be dispelled as follows. The theory states only that if an artist designates some object or event, 'artwork', then it is an artwork. It does not follow from this, however, that his or her motivating theory about what counts as art must also be generally valid. In other words, from the fact that an artist can create an artwork by designation, it does not also follow (on the terms of the theory) that he or she can designate some object 'not artwork' with the same necessity. This, in fact, turns out to be one of the strengths of the theory. Whereas most definitions of art would exclude certain objects which might count as art under other definitions, the Designation theory can encompass them all without inconsistency.

A better line of criticism is as follows. If (and only if) artists are entitled to create artworks by acts of designation alone, any object so designated would be an artwork. However, the very entitlement to do this is assumed rather than argued by Danto et. al. Against them we can cite the fact that the inclusion of some object in a given ontological class ' $x$ ' is generally founded on the object's perceptible properties as 
such, or, in the case of an artifact, the artifact's possessing perceptible properties ostensibly suited to the function for which artifacts of that kind are created. (Let us call this, the Argument from Design.) On these terms, the status of an object or artifact as an instance of class ' $x$ ' is not simply a ghost which lurks in a machine of perceptible properties, and which can float to an object or artifact of another sort simply by an act of designation. Rather it is a necessary condition of conferring the status 'member of ontological class " $x$ ", that we make such an ascription on the basis of the object or artifact's possession of appropriate perceptible properties; or by creating an item in accordance with such a specification.

Now some proponents of the Designation theory (such as Danto and, more ambiguously, Dickie) hold that 'art' is indeed an ontological class, but one whose members are grouped together by virtue of 'non-exhibited' contextual properties, rather than straightforward perceptible ones. On these terms, by being designated as 'art' and placed in an art context, Duchamp's Bottlerack is now a member of the ontological class 'artworks' rather than that of 'bottleracks'. This cavalier notion of ontological status, however, clearly contradicts the necessary condition which I suggested as the basis of such ascription. Can it be justified, then? Let us consider the example of a pebble which is designated 'paperweight' and placed on a desk, but without ever actually being used as such. Let us consider also a biscuit which IS put into service as a paperweight. Now if the Danto - Dickie account were correct, the pebble and biscuit have now taken on a new ontological status - as members of the class of paperweights. But is this really so? One can, of course, designate all sorts of classes and instances of classes e.g. my pen is a member of the class of objects present in this room. Designations of this kind, however, have no ontological potency - they bring no new entities into existence. Instead, they orientate us towards, or make explicit, what is already actual. Similarly, if we intend, or use, our pebble and biscuit in a way characteristic of some other object, we do not, thereby, create a new existent. To suppose that we do, is, (through mere linguistic idleness) an unnecessary multiplication of entities in an already bloated universe. For example, stated properly, our examples should emerge as 
a) ' $x$ ' is a candidate for use as a ' $y$ ' (the pebble)

b) ' $z$ ' is being used as a ' $y$ ' (the biscuit).

Put in this parsimonious way, we find that the pebble and biscuit are just what they seem - a pebble and a biscuit. If use and designation alone really were the determining criteria of conferring ontological status, it would be difficult to see how communication would ever be possible. Our classification of what kinds of thing there are would be so fluctuating and dependent on the context of use or designation, as to lead, at least to a kind of contextual solipsism.

The foregoing parsimonious interpretation has fascinating consequences when applied to art. Clause a) throws the fundamental problem which the Designation theory obscures, into clear relief; namely that if an object is offered for use as art, it has at best the status of a candidate. Whether it will fulfil or not the qualifications for art, is another matter entirely. This would involve referring the designated object to the already existing definition of artworks - which, as Danto and Dickie both admit, is the imitational theory. There is little doubt that designated 'art' objects would fail to meet such a qualification.

It is also interesting that the Danto/Dickie approach seems to preclude us from saying (in the spirit of clause b) that 'This is being used 'as' (in lieu of) (a proxy for) (as if it were) that'. On their terms, by using an ' $x$ ' as a ' $y$ ' ' $x$ ' becomes a ' $y$ '. There are, of course, many cases which throw the inanity of such an assimilation into clear relief. For example, suppose that to enliven what promises to be a dull college dinner, I take flowers from the vase and offer them to a guest as 'the hors d'oeuvre'. Now the whole point of this gesture is not that the flowers have become the hors d'oeuvre, but precisely that they are not. In other words, to see the gesture as actually conferring a new ontological status on the flowers, would be exactly to miss its (admittedly weak) humorous point. This, as I shall suggest later, has interesting - perhaps devastating - consequences in relation to Duchamp's readymades.

The point to gather from all this is that the status of 'an instance of ontological class"x", is one that cannot be conferred by mere use or act of designation alone. If, therefore, as Danto (explicitly) and 
Dickie (implicitly) admit, art is an ontological class, then it would follow that their claim that the status 'artwork' can be conferred by designation or use alone, is inconsistent. It is one thing to designate something as an artwork, and another thing entirely for that artwork to be so in reality. Before this can occur, the artist must configure material into an artifact bearing the appropriate perceptible properties i.e. he or she must make it. What the Designation theory tries to do, is construe the relationship between designation and artwork on something like the same basis, as that between the idea of God and His necessary existence in the Ontological Argument. Now this is rather more than a mere ro mantic notion of the artist as 'godlike'. It attributes capacities to the artist which actually would only be meaningful as attribute of God Himself. This might, indeed, provide the basis of a very interesting argument that designated 'art' is, by its very nature, blasphemous (or even Satanic) in attempting to usurp the Divine prerogative. I do not, however, have the space or inclination to follow up such an argument. What I shall say is that whilst real existence being entailed by the mere positing of it, may make (at least hypothetical) sense in the context of God it does not do so in the context of the intentions and desires of human being. The finite world, in other words, must be bound by those criteria for conferring ontological status, which I have called the Argument from Design.

Clearly, the only way to avoid such a conclusion, is by providing a very convincing 'deduction' of the artist's entitlement to deviate from this established ontological framework. Proponents of the Designation theory approach this deduction in two ways. First, it is assumed that art is by definition (or 'analytically') unlimitedly creative. To tie it to a class of artifacts possessing specific perceptible properties is, therefore, to limit art's possibilities. Indeed, Danto suggests that to define art by virtue of such properties

... is incompatible with revolution, and it is analytical to the concept of art that the class of artworks may always be revolutionised by admission into it of objects different from all hitherto acknowledged artworks. ${ }^{1}$

1 Arthur Danto 'The Transfiguration of the Commonplace', Journal of Aesthetics and Art Criticsism, XXXIII, (1974), p. 141. 
Now it is surely true that all human activities can be characterised as 'creative' insofar as their end products exemplify originality and imagination in conception and execution. When such creativity is sustained and of a high order, it will naturally set in motion a shock-wave of influence which will bring about a 'revolution' within that field of activity. This suggests that our usual notions of creativity and revolution are not absolute, but operative within the boundary conditions which define the kind of activity in question. This has certainly been true of the visual arts until the time of Duchamp and Dadaism. We had revolutions of style, rather than ones which admitted into the artworld 'objects different from all hitherto acknowledged artworks'. Why, then, should we admit the Designation theory's absolute sense of creativity and revolution? Presumably because art itself took such a turning. But did it? And if did, were artists entitled to make such a move? This returns us, in other words, to the problem of why art should be exempted from our usual criteria of classification - a problem which the 'deduction' should actually be solving.

It is instructive to bear in mind here, that when an innovation really does utterly transform an activity, we usually accept it not just as a revolutionisation of the activity, but as the birth of something new. Our classificatory vocabulary, however, sometimes takes time to catch up with the implications of such an event. Galilei's theories, for example, broke down the boundaries of medieval philosophy and inaugurated a new way of understanding the world. However, as late as the nineteenth century this new activity was still being called 'natural philosophy', despite the fact that Newton's system had established its distinctive methodological principles. New from a modern point of view it would be absurd to describe such physical science as 'philosophy' and apply to it the criteria used for judging philosophical arguments. It seems, however, that the Designation theory is making just this sort of demand in asking us to see the Duchamp/Dadaist revolution (and its tradition) as something artistically different, rather than the beginnings of some zany meta-critical activity which is different from art. Indeed, the criteria for ascribing 'creativity' to works in the Duchamp tradition, are notoriously elusive. One supposes that in time the 'artworld' may evolve such criteria, on the basis of things like a show of credit cards, or a 
weighing of names dropped by the 'artist'. But this is indicative only of the inherent shallowness of the Artworld. Hegel, in contrast, spells out the real source and structure of artistic creativity.

The universal need for art ... is man's rational need to lift the inner and outer world into his spiritual consciousness as an object in which he recognises again his own self.1

Unfortunately, the 'unlimited' creativity of the Duchamp tradition of 'art' takes the form of an ever-accelerating annexation of the outrageous and the incongruous for its own sake. This self-perpetuating momentum makes 'creativity' into a merely formal notion, and alienates the 'artist' from the truth of his or her own labour. Indeed the creativity ascribed to designated works is frequently only a reflection of pseudo-virtuosity on the part of the critic. On these terms, creativity and revolution become wholly second-order - a function of 'art talk' rather than artworks.

This shallowness leads directly to the second aspect of the 'deduction' of the Designation theory. It is claimed that if some object or event is encompassed by an act of art designation, it is, thereby, no longer a real object or event pure and simply, but one with emergent properties of a referential sort. It becomes a work of art by virtue of being a 'statement' about art. ${ }^{2}$ However, suffice it to point out that even if a link between statements and designated 'art'(or indeed non-representational 'art' of any sort) were established, it would only set the fundamental problem at one remove. We would still have to justify why, in contradiction to the Argument from Design, we are justified in regarding statements about art 'as' works of art. It seems to me that what proponents of the Designation theory are really saying through this 'deduction', is that if designated works are really art, then it can only be by virtue of their being statements about art. Stating the 'deduction' in this way, however, points directly to that cathartic Heresy to which I have already alluded. Perhaps 'designated' works are not in

I G.W.F. Hegel, Aesthetics trans. T.M. Knox (Oxford: Oxford University Press, 1975) p.31.

2 Claims of this sort occur, in all three of Danto's papers (op. cit.) and also his 'An Answer or Two for Sparshott' Journal of Aesthetics and Art Criticism, XXXV (1976) pp. 80-82. See also H. Gene Blocker, op. cit. 
fact artworks at all, but rather the embryonic manifestations of a new and zany meta-critical activity, founded on the ironic appropriation of real things. To label such works 'art', in the manner of the Designation theory, proves, in fact, only the entrenched conservatism of the artworld and its theologians. To take, for example, a piece of 'junk' sculpture, as significant primarily through having emergent properties that refer to the artworld, is to fit such objects into the mould of our expectations of traditional art - namely that it is, or at least ought to be 'about' something.

There is, however, one line of justification still open to the artheologian. Timothy Binkley in his paper 'Piece: Contra Aesthetics' proposes a version of the Designation theory as follows:

To be a piece of art, an item need only be indexed as an artwork by an artist. ${ }^{1}$

Now whilst Binkley tends to look upon the item so 'indexed' as, in some sense, a statement about art, he does not hang the burden of justification upon this alone. Instead he argues that the real foundation of the definition of art lies not in the properties of a certain ontological class but rather in the more loosely structured notion of cultural practice.

A work of art cannot stand alone as a member of a set. Set membership is not the structure of that human activity called art. To suppose we can examine the problem of art by trying to explain membership in a class of entities is simply a prejudice of aesthetics, which underplays the cultural structure of $\operatorname{art}^{2}$

But what, we might ask, is the basis of this 'cultural structure'? Binkley's answer to this is not as detailed as one would like, and reduces to the claim that '... the general focus of art is creation and conception for the sake of creation and conception.'3

Let us review this. We might start by pointing out that the concept 'art' is itself a product of certain historical phases of western culture. But why should we have ever devised such a term? What use could it serve? Well, western civilisation (through its technological ad-

\footnotetext{
Binkley, op. cit., p. 273.

2 lbid., pp. 271-272.

3 lbid., p. 274.
} 
vances) is uniquely rich in knowledge. This privileged vantage point enables it to observe not only the ideosyncrasies of itself and other cultures, but various social phenomena of a transcultural nature. For example, the practice of making mimetic works (i.e. artifacts which refer to objects other than themselves, by virtue of some broad notion of visual resemblance) is one which is common to at least western, Asian, and some Central American peoples. Now although such artifacts may be created and used for widely contrasting purposes, and may vary the basic convention quite radically (e.g. by using or not using perspective) they have, nevertheless, a basic likeness of sensible properties. Similarly, within the purview of different historical phases of our own culture, it has frequently been noted that the mimetic aspects of visual representation have an underlying affinity with the literary use of language, and with music. What this suggests, of course, is that mimetic artifacts constitute a distinctive class of entities, that cuts across different epochs, different cultures, and different media. I am suggesting, therefore, that our own culture has evolved the term 'art' (or more appropriately 'fine art') to pick out just this distinctive transcultural mode of sensuous reference. Given such an historical 'deduction' of the concept 'art' it becomes clear that Binkley's justification of the Designation theory is illfounded, and that we still require a convincing explanation of why designated 'art' should be allowed as an exception to our established rules of ontological classification. Binkley's claim about art being essentially creation or conception for its own sake, rings especially hollow - unless (as I shall show in my next Chapter) the object of such creation can be analysed in terms of properties which have intrinsic human significance. Indeed, it is also the case that definite cultural practices (as well as objects and artifacts) can only be learnt, individuated, and meaningfully discussed on the basis of properties which enable us to distinguish between correct and incorrect instances of the practice. On Binkley's terms, however, no such properties could exist, and hence it is entirely inconsistent for him to even talk of art having 'structure'.

This point directly to another of the Designation theory's manifold obfuscations. What its proponents do, in effect, is to project the dogmatic assumptions of their own historical epoch on to art as such - thereby distorting its transcultural specificity. The idea of art 
created by designation alone is one which could only arise in a society founded upon mass-production. The Designation theory serves the needs of a 'laid-back' leisured class who require a push-button art to reflect and legitimise their 'push-button' lifestyle. In such a consumer society artifacts are encountered primarily as objects for consumption whose 'made' or unique sensuous character is overlooked or fetishized. They appear to have simply popped into existence, at the behest of some consumer desire. Small wonder, then, that the artist should carry this attitude into the context of his or her own labour, and that the art-theologian should pronounce benediction upon it. Why trouble to exert oneself when an 'artwork can simply be desired into existence? This concept of creative labour, however, is one which is completely alien to most epoches of our own art-history, and perhaps more so to the artifact creating practices of other cultures. To construe it, then, as 'the general focus of art' is an instance of exactly that sort of cultural prejudice which the Designation theory prides itself on avoiding.

If, at the end of all this, the art-theologian persists with his or her view, we must raise the question of what might be called the "paradox of the total "artwork". This involves an artist who designates 'all that is, was, or ever will be' as an artwork. This Great Designation means, of course, that any subsequent artworks will be either a part, or a copy of a part, of the total artwork. The implications of this for the Designation theory are acute. Any artist who creates a piece after The Great Designation, will not in fact be creating an original work. Far from being (as the Designation theory holds) right, he or she will be necessarily wrong. Indeed, on Danto's version of the argument, art will have come to an end - not by self-congruence (a la the self-knowing Hegelian 'Geist') but by a failure to meet the condition of being an original work.

The legal implications of all this, are also fascinating. If the Great Designation is valid (and on the Designation theory's terms, it must be) then any artifacts - including philosophical papers, that are subsequently produced without the express permission of The Great Designator, will be in breach of copyright. We philosophers would find that 
... by a curious astounding magic, we have been made over into contributors to a field we had always believed it our task merely to analyse from without. ${ }^{1}$

Danto takes this 'field' to be the creation of art. I suggest that it is more likely to be the field of litigation.

The irony of this outcome to the Designation theory would have been greatly appreciated by Duchamp. The creation of his 'readymades' was a gesture probably intended to poke fun at the reverence we afford art, rather than to push art in a new direction. ${ }^{2}$ On these terms, the readymades make their point precisely because something demonstrably not an artwork is paraded as if it is one. But consider the following remark of Binkley's:

Duchamp selected several common objects and converted them into art simply by indexing them as artworks. ${ }^{3}$

Similarly, Dickie's comment that

Duchamp and friends conferred the status of art on "readymades" ... and when we reflect on their deeds we can take note of a kind of human action which has until now gone unnoticed and unappreciated - the action of conferring the status of art. 4

These remarks (which are entirely characteristic of the artworld's general approach to Duchamp) make an assumption as to his intentions which entirely misses the readymade's point; yet it is this very assumption writ large which is amplified - with disastrous results - into the Designation theory of art. If this assumption were correct, we should, by the same logic, allow that the flowers I playfully offer to my guest really are the hors d'oeuvre; or that the stuffed lizard which has been lovingly labelled 'The Professor of Sociology in this University' really is the same careerist who annoys us so at Senate meetings. 5

1 Danto, 'Artworks and Real Things' in Dickie and Sclafani, op. cit., p. 562.

2 Paul Humble arrives at a similar view in his 'Duchamp's Readymades: Art and Anti-Art', British Journal of Aesthetics, Vol. 22, No. 21 (1982), pp. 52-64.

3 Binkley. op. cit., p. 275.

4 Dickie, op. cit., p. 32.

5 For further animadversions of this theme, see the critique of Dickie in Part One of my 'Art and Autonomy', British Journal of Aesthetics, Vol. 21 , No. 2 (1981), pp. 12-21. I should also point out that there is no Professor of Sociology in the University of St Andrews. 
It might, finally, be objected, that if Duchamp had really intended his readymades as anti-art in the sense I have suggested, then he would have drawn the artworld's attention to its mistake. But of course, he would not - because

1) It made him famous.

2) It made him money.

3) It made him laugh.

We conclude, therefore, that the joke is on the art-theologians, and the Designation heory rests on an art-historical mistake. Given this analysis, the task which now faces us is to define and clarify art on its proper ontological and historical basis - as a mode of mimesis. The best source for such an investigation is within the traditions of existential and hermeneutic philosophy. It is, therefore, to one such tradition that I now turn.

\section{II: ART AS A FORM OF KNOWLEDGE Part One}

In the 1930's Heidegger offered an account of the relation between truth and art working from the assumptions of his own variant of existential phenomenology. We are told of Van Gogh's famous painting of peasant boots for example, that

Van Gogh's painting is the disclosure of what the equipment, the pair of peasant shoes, is, in truth. This being emerges into the unconcealedness of its being ... If there occurs in the work a disclosure of a particular being, disclosing how or what it is, then there is here an occurring, a happening of truth at work.... 1

Now what is significant is that Van Gogh is not simply describing or stating a series of facts about certain objects in the lived.world, but rather letting them emerge into human experience as Truth.

1 Martin Heidegger 'The Origin of the Work of Art', in Poetry, Language, Thought, trans. and ed. A. Hofstadter (New York: Harper and Row, 197), pp. 17-81. This reference, p. 36. 
The reader may well feel some suspicion of 'truth' used in a context so removed from its usual epistemological domain. Let us consider, then, in what sense 'truth' is being used here. Imagine the following situation ... Without saying anything I place an object on the table in front of us. I turn it around to reveal its various aspects, or move it closer to you to study as you wish. In this context, it could be said that I am showing or revealing the object to you, rather than indicating or stating facts about it, such as 'this surface is dirty' or 'I think this is used for ... (such and such purpose)'. In other words, before putting it to use, or making it the object of propositions or judgements, I am actually bringing it to presence. It is in this sense of an act of bringing-to-presence that Heidegger talks about truth 'happening' in a work of art. Indeed, the very notion of bringing-to-presence lies at the root of Heidegger's whole conception of truth and Being, and of the importance generally afforded to pre-predicative experience in existential phenomenology.

There are, however, a number of shortcomings in Heidegger's account, which I shall now briefly comment upon. ${ }^{1}$ First, the kind of aesthetic encounter with Truth which Heidegger describes is of a very narrow and particular kind. (Elsewhere, I have termed it 'aletheic experience'). ${ }^{2}$ However, whilst this is one feature of our encounter with truth in art, it is by no means fundamental. This points directly to a second problematic area. For a work to have the disclosive significance which Heidegger notes, it is logically presupposed that this significance emerges through the work's relation to two contextual horizons - that of the specific medium and its traditions, and that of the artist's creative individuality. Heidegger does allow that the 'createdness' of the artwork should be manifest, but he does not make any real allowance for the role of the two horizons (just noted) in defining and declaring this createdness. What makes this omission so serious is that if we are to grasp what is essential to artistic truth qua artistic, we must surely make the role of the individual creative vision paramount. Failing this, artistic

1 For a fuller discussion see Chapter Five of my Art and Embodiement; From Aesthetics to Self-Consciousness (Oxford: Clarendon Press, 1993).

${ }^{2} \mathrm{See}$ chapter Two in Crowther (Ibid.). 
value is simply interpreted on the model of that which (in Heidegger's terms at least) characterises authentic philosophical knowledge.

Fortunately, Heidegger's approach has been refined in the direction of the two horizons noted above by Gadamer in his monumental Truth and Method. I shall now expound, and then develop some ideas from that work.

First, Gadamer's major positive strategy is to explain the essence of art by articulating its ontological structure. He finds the clue to this structure in the phenomenon of play. By play, Gadamer has in mind such things as children's games, sport, chess - any activity, in fact, which is both pursued for its own sake, and self-enclosed (in the sense of carrying rules to which the players must conform). Gadamer further holds that whilst play is founded on behaviour tied to the realization of specific goals, its meaning cannot be reduced to such goals. It is rather a function of the event of playing itself. The game takes hold of the players, and, through them, achieves a kind of 'self-representation'. In this narrow sense, of course, all play is representational, but, as Gadamer points out, some games are representational in a stronger mimetic sense - for example, children's make-believe.

There are, no doubt, some grounds for disputing that play is a self-representational activity (or at least for claiming that it is no more so than any other form of human activity). However, this objection would not affect Gadamer's basic strategy. For given that there is such a thing as representational or mimetic play, the key step which he must make is to show how this illuminates the ontology of art. The step is taken as follows. Gadamer claims that art is the highest form of representational play, and in it, play achieves 'ideality' and 'transformation into structure'. Now whilst his arguments in relation to this are, unfortunately rather unwieldy, their substance amounts to the following...

First, mimetic play in general can be defined as a rule-governed activity which achieves reference to some aspect of the world other than itself. For Gadamer, artistic representation is an activity of this kind, but one which issues in the production of symbolically significant artifacts. It is this latter fact which gives art its special status for it embodies a threefold relation between the artist, the world in general, and the audience. When representational play issues in an art- 
work, it is no longer an unstable event in progress, but rather a concrete set of mimetic relations which have become autonomous from the specific conditions under which they were produced, and which are now permanently accessible to a general historical audience.

This amounts to a 'transformation into structure'. The reason for this is not only that the artwork's content is embodied in a material concrete form, but also because the content is clarified. In representational play '... what is, emerges. In it is produced and brought to light what otherwise is constantly hidden and withdrawn'. ${ }^{1}$ For Gadamer, this involves a process of recognition, wherein '... what we know emerges, as if through an illumination, from all the chance and variable circumstances that condition it and is grasped in its essence'.?

Now in the case of art, this illumination of the content's essence, is not simply a case of recognizing what kind of content is being referred to; nor is it a case of Heideggerian disclosure. Rather the artist's particular style of articulating his or her medium is decisive. As Gadamer puts it ${ }^{3}$ the presentation of essence, far from being a mere imitation, is necessarily revelatory. When someone makes an imitation, he has to leave out and to heighten. Because he is pointing to something, he has to exaggerate whether he likes it or not. Hence there is an unbridgeable gulf between the one thing, that is a likeness, and the other that it seeks to resemble'. 4 The crucial implication of these remarks is that in art, the revelation of essence centres on the artist's experience of content. The finished work refines content in the direction of what the artist takes to be its essential features vis-a-vis his or her relation to the world and to the artistic audience. Indeed, Gadamer sees the artwork as exemplifying the essence of experience itself. For example, in relation to the aesthetic reception of art, we are told that

1 Hans-Georg Gadamer, Truth and Method trans. William Glen-Doepel (London: Sheed and Ward, 1979). The most relevant area of this work is Part One, Section II, sub-sections a) and b).

2 Ibid., p.101.

3 Ibid., P 102.

4 Ibid., p.103. 
Precisely because it does not combine with others to make one open experiential flow, but immediately represents the whole, its significance is infinite. ${ }^{1}$

And that the experience of art is the 'perfecting of the symbolic representation of the whole of life towards which every experience tends'.2

Now before considering what is problematic about Gadamer's position, I shall indicate something of its great strength. First, Gadamer's account is one which preserves a sense of the continuity between creative process, art object, and audience. It declares the fact that all art has an event-character wherein the concreteness of the work qua work mediates the different interpretative horizons of creator and recipient. More than this, Gadamer's account broadly indicates art's vital function in the continuity of what I shall call world-projection. Let me explain this notion and thence develop Gadamer's position. To be self-conscious is a function of the co-ordination of our sensory and linguistic capacities. This means that any moment of awareness and cognition has both a sensuous and a conceptual/symbolic dimension. In most cognitive situations these dimensions will be very evenly balanced, in other situations one or other of the two elements will preponderate. For example, in making mathematical calculations, or in problem-solving (in both practical or theoretical contexts) the conceptual element is to the fore, insofar as we are striving to deductively analyse or inductively generalise about items and their relations. Here, in other words, our capacity to comprehend instances of sameness and difference per se is the decisive element in cognition. There are other states of consciousness, however, where the conceptual core is much more weighted by the sensory dimension. For example, every moment of awareness is informed by latent knowledge concerning alternative possibilities of perception. This involves our ability to recall past experiences, and to posit future ones, and to project possible perceptual situations co-extensive with, but beyond the reach of our immediate position in the phenomenal field. Now whilst the ability to project beyond immediate perception in these terms, can be purely a process of thought, its more fundamental mode is the image. An image is a mental state

1 Ibid., p. 63.

2 Ibid., p. 63. 
which refers - and thence has a symbolic or conceptual content - but which does so on the basis of mimesis. It has something of the sensory vivacity of immediate perception itself. Indeed, it may be that thought itself has its phylogenetic origins as a refinement of image-mimesis. The realm of imagery - be it exercised in memory or imagination - is the zone from which rationality emerges.

On these terms, then, the life of self-consciousness finds its very flesh in imagery. Through memory and imagination we project a world of past actualities and alternative perceptual possibilities - a latent existential space - which informs and shapes our actual passage through the world. It is this world -projection which finds extension in the notion of play. Games, sport, make-believe and the like are objectifications or instantiations of our capacity for world-projection.

Now we will recall that Gadamer sees play as the clue to the ontological structure of art. This is a major insight. For in linking play to art, he is, in effect showing that art has its origins and structure in an element which is fundamental to self-consciousness itself. In affirming this, Gadamer is preparing the ground for a proper understanding of what separates artistic truth - claims from those which characterise other forms of knowledge. The key point here is that art stems directly from the experience of shared subjectivity - from a mutual recognition of common forms of relatedness to the world. Such recognition involves a kind of seeing the world from where the other sees it. At the heart of this experience is the fact that, in art sensuous embodiment and symbolic content are necessarily related. In effect, Gadamer is following up and redirecting Hegel's most general position on art namely that it is a mode of knowledge midway between the sensuous immediacy of material things and the abstractness of pure thought. This is correct. What is distinctive about art as a form of knowledge is that it is not a body of abstract truths derived by generalisation or deduction from sets of relations; nor is it a simple item present to the senses in purely material terms. Rather it is a function of the zone of imagery - of world projection - where abstract thought itself emerges from a mode of more corporeal and sensuous mimetic reference.

Whilst Gadamer's theory directs us towards art's distinctive status as a form of knowledge, it has, nevertheless some shortcomings. For 
a start, the points which I have just made vis-a-vis art's relation to self-consciousness and world-projection are only indicated by him in the most general and schematic terms. A more serious worry concerns his claims about the artwork exemplifying the essence of experience. A claim of this sort is necessary, insofar as art transforms play into 'structure' i.e. it is a full realization of tendencies which are only hinted at in play and games. Only in art, in other words, does image-mimesis attain the status of knowledge. But why is this so? We will recall that Gadamer suggests that in the artwork we find a revelation of essence, which, in our experience of it, does not simply combine with other experiences in an 'open experiential flow'. Now the very fact that the artwork is a symbolically significant artifact means that we do not experience it as we would an ordinary material thing. This, however, does not, of itself, explain why - as Gadamer also holds - the artwork is a symbolic presentation of 'the whole of life, towards which every experience tends'. Until this point is clarified, the exact determination of art's status as a form of knowledge remains incomplete.

In this respect Gadamer does offer us one further illuminating clue in the course of his discussion of the visual arts. Consider the following remarks concerning picturing - '... now that the original is represented, it experiences, as it were, an increase in being ... if it represents itself in this way, this is no longer any casual event, but is part of its own being. Every such representation is an ontological event and belongs to the ontological level of what is represented'. ${ }^{1}$ Gadamer is here making a metaphysical point derived from neo-Platonism. The subject of the picture is a 'one' from which the picture itself is an emanation of overflow. Given this '... if what is originally one, does not grow less from the overflow of the many from it, this means that that being becomes more'.2 Now stated in this metaphysical way, there is much about Gadamer's point which is puzzling and obscure. Not least of his problems is the fact that whilst by definition pictures are of a recognisable kind of subject-matter, this does not presuppose that the subject is an original in the sense - which Gadamer clearly intends - of being actu-

1 Ibid., p. 124.

2 ibid., p. 124. 
ally existent. Many pictures for example, are of imaginary subjects. However, if we interpret Gadamer's metaphysical point in an ontological or existential sense, a clearer set of possibilities emerge. On these terms, if we regard the artist's experience of a subject-matter (be it real or imaginary) as the original, then we might see the artwork which results from this as a kind of 'increase in being' for the original. This interpretation indeed, would also allow Gadamer's point to encompass artworks in addition to the visual. Having made this move, then, I shall now address the task of reinterpreting Gadamer's 'increase of being' in ontological terms.

\section{Part Two}

Every moment in human experience is determined and given its specific character by its relation to all the moments which preceded it, and by its relation to expectations concerning non-immediate perceptual situations and the future in general. Its own identity as a particular, in other words, implies a sense of the totality of the experiential subject's life. However, it is one thing to imply the totality of life, and another thing entirely to symbolize it. True, there are privileged moments in any person's experience, wherein one feels oneself to be at a crucial stage in existence - one towards which the totality of events in one's life so far have been, as it were, pointing; and around which future events will constellate. This awareness of totality is, however, fragmentary, and quickly submerged in the general experiential flow. Hence, if the whole of a person's experience is to be symbolised in a full sense, it must be through a medium which, whilst being something directly present to the experiential subject, is also in some sense autonomous from his or her experience. It must, in other words, be made into an artifact.

Now as I noted in Part one, for Gadamer the artwork is, in effect, a continuation of that capacity - necessary to all self-consciousness - which I called world-projection. It is an artifactual image. This means that it is a symbolically significant sensible manifold - an item wherein overt symbolic or referential content is sensibly embodied, on the basis 
of communicative conventions. It is thus ontologically akin to the world-projection aspect of experience, whilst, at the same time, being physically autonomous from its creator. The significance of this, of course, is that in artifact form, the image endures. Indeed, it embodies an overt symbolic content which (in a way that a mundane artifact does not) invites interpretation. Already, therefore, we can see how in art experience might be said to enjoy an increase of being.

However, this is only the most basic level. Before we can consider further ontological senses of increase of being, we must first clarify the scope of the term 'image' in its artistic context - as symbolically significant sensible manifold. The most striking exemplar of this notion is pictorial and sculptural representation. Here sensible material is worked up into a symbolic formation on the basis of specific communicative codes founded (through same of course, would dispute this) upon visual resemblance. It is important to understand the very broad scope of this. For it encompasses much of what is generally called abstract art. All shapes, colours, masses, and textures have ranges of action or feelings associated with them. This associational reference is not codified to the same degree as in 'normal' pictorial or sculptural representation; it draws rather on much looser conventions that are part of an individual's general cultural stock. These range from seeing abstract forms in terms of biomorphic imagery, to reading geometric shapes and masses in terms of stability versus virtual motion or presence versus void.

Similar considerations also apply in the case of music. Susanne Langer has suggested that

The tonal structures we call "music" bear a close logical similarity to the forms of human feeling - form of growth and of attenuation, flowing and stowing, conflict and resolution, speed, arrest, terrific excitement, calm ... Music is a tonal analogue of emotive life. ${ }^{1}$

Langer's final remark here is unnecessarily parsimonious. Music is a tonal analogue of experiential temporality per se. It presents a loose temporal and acoustic image of patterns of action and gesture - of

1 Suzanne Langer, Feeling and Form (London: Routledge \& Kegan Paul, 1953), p. 27. 
progress and obstacle - as well as structures of mood and feeling. In western cultures the tonal system is learnt from childrenhood in terms of associations of this sort. Likewise the quasi or neo-tonal scales of non-western cultures. Such associational logic even permeates our hearing of, serial, or aleatory pieces. If one has knowledge of the appropriate code one can discern patterns of growth and repetition, presence and absence, that enable a work to be interpreted in a mode similar to that engaged by visual abstract art. Even if one does not know the appropriate code, such pieces can be experienced in terms of a discourse of alienation, rejection, or fragmentation, that actively plays off against the grounding of our expectations in the tonal system.

The image-character of literature is rather more complex than the visual arts and music, since here elements of a pre-given symbolic formation - namely language itself - are made into a sensible manifold. But why describe literature as sensible or sensuous in a way that the ordinary linguistic utterance is not? Let me consider first the example of poetry. It is one thing, say, to describe the experience of love or a visit to Slovenia, and another thing entirely to make these experiences - real or imagined - into a poem. The crucial point is that in making a description we are consuming the description in its referential function; but in writing a poem, in contrast, we are seeking to articulate and preserve an actual or possible personal experience of love or Slovenia, or whatever. In poetry we are concerned not just with ideas and relations but with the poet's personal experience of these, and, in particular his or her style of language. We are invited, in other words, not just to recognise a meaning or set of meanings, but to inhabit the poet's experience of them - to share a way of seeing the world. This solicitation, indeed, is a necessary part of the meaning.

Similar considerations apply in the case of narrative literature. The world is projected for us in terms of imagination - an address to the feelings, senses, and intellect in concert - rather than the factual schemas of the intellect alone. For example, the novelist does not simply present us with a narrative and then (as it were, in parenthesis) indicate the various significant events, actions, and motives which determine the structure of the narrative: Rather he or she welds these together in a unified succession of images. We encounter the salient 
events of the plot, hatched out from a matrix of other events. As Merleau-Ponty observes

The function of the novelist is not to state ... ideas thematically but to make them exist for us in the way things exist. ${ }^{1}$

I am arguing, then, that all art has the character of image. It is a stabilized and enduring mode of world-projection, wherein a sensible manifold and a symbolic content are inseparably combined. Having, then, clarified the scope of art as symbolically significant sensible manifold, we can now consider the further complex senses in which, through it, experience achieves ontological increase of being.

The first of these pertains to the subjective aspect of the artist's creativity. It is crucial to note that the artwork is not simply an external analogue of some completely pre-given private experience. Again, Merleau-Ponty usefully observes that

As for the novel, although its plot can be summarized and the "thought" of the writer lends itself to abstract expression, this conceptual significance is extracted from a wider one, as the description of a person is extracted from the actual appearance of his face. ${ }^{2}$

This point can be generalised to all the arts. The creator has an intention to create, to produce an image addressing such and such an area of his or her experience, or imagined experience. This intention guides the creative process, but in the course of working the material, it may be changed, reinterpreted or even totally transformed. The finished artwork, is, thereby, more than a sensible surface which addresses a certain range of experience. For the artist knows that his or her work did not simply happen as the sum of an accumulation of discrete moments. Even if the work is formally or technically simple, it condenses and preserves data drawn from experience reaching deep into the artist's past and projections of the future, and embodies them in the unity of the present finished artwork. The work is thus, subjectively speaking, a symbol of the whole of the life which informs it.

1 Maurice Merleau-Ponty, Signs, trans. Richard C. McCleary, (Evanson: Northwestern University Press, 1964), p. 46.

2 Maurice Merleau-Ponty, Phenomenology of Perception, trans. Colin Smith; revised by Forrest Williams, London: Routledge \& Kegan Paul, 1974), p. 151. 
This subjective increase of being for the artist's experience, has an objective counterpart for his or her audience. In this respect, the audience recognises that sensible form with such and such a significance is being addressed. However, the artist's particular style is one which interprets this significance. It serves - in Merleau-Ponty's fine phrase - to 'carve out relief in things'. Now it is often remarked upon by formalist aestheticians that the enjoyment of organic unity per se is fundamental to the aesthetic experience of art. This is true, but it is by no means the whole truth. For given the fact that the artwork itself is an event of interpre tation in the sense just described (and also discussed in relation to Gadamer in Part One) its organic unity takes on a deeper significance. The artist has articulated his or her subject in just this way. $\mathrm{He}$ or she offers us a personal vision of what is of aesthetic worth or broader human significance in the subject. However, this vision is not something simply imposed on, or translated into the work. Neither is it simply the sum of the parts. Rather it emerges as a unity from the parts, even as (qua organisational principle) it determines the particular character of those parts. The audience knows further that this emergence is of futural significance. It may change the way we experience our own lives. It may even be subjected to radical reappraisal by generations yet to come. All genuine interpretation is effective history.

Now the point to gather from all this is that at an objective level the artwork symbolises the totality of human life in a kind of qualitative sense. It exemplifies the way in which particular experience necessarily emerges from a network of broader relations - both subjective and objective - to which it gives a determinate character, and which it situates in terms of anticipations of the future. On these terms the artwork reflects the basic structure of experience. It presents that structure not in abstract factual terms but as an object at the level of perception. This means that in the experience of art, the truth of experience itself is grasped at the ontological level that is fundamental to self-consciousness - namely the embodied subject's reciprocal interactions with the sensible realm in which it inheres. In art, experience increases in being in the sense of attaining self-possession.

I have argued, then, that art is to be defined as that mode of artifice which issues in the production of symbolically significant sensi- 
ble manifolds. Its uniqueness as a form of knowledge consists in its capacity to reflect structures which are necessary to self-consciousness. There is considerable room for developing this line of argument in the direction of philosophical anthropology. On these terms one would argue that the production of artis not some luxury accomplishment, but is inherent in the development of reason and advanced cognitive competences.

However, I shall not take this point any further since by present task is not yet complete. The reasons for this are complex. From the foregoing analysis it will be clear that the term 'art' describes an ontological class. However, this descriptive approach is not a sufficient analysis. The problem here is that the concept of art also has an evaluative dimension, as exemplified in the distinction offen drawn, between the products of mass culture and those of 'high art'. For present purposes, one could put the problem like this. Kitsch paintings, pop songs, t.v. soap operas and the like can all be legitimately described as symbolically significant sensible manifolds, but the term 'art' would seem to be travestied if applied to them. Now whilst in general terms this is true, a crucial qualification must be made. There are subjective conditions under which kitsch and soap opera and the like can take on the kind of reflective ontological significance which I have described in relation to art. We may attend to them in these terms as a result of them having some special private significance for us or because one is something of a connoisseur in relation to certain genres of kitsch. However, this is the exception rather than the rule. The majority of symbolically significant sensible manifolds are created for quite specific functional ends such as escapist entertainment, decoration per se, or social and/or religious ritual. However the very evolution of the concept art and the artworld itself shows that some functional artifacts can transcend their functionality in the reflective direction which I have described, and, indeed, that art can be pursued as an end in itself.

The task which remains, then, is to clarify the conditions under which art in the general descriptive sense becomes art in the evaluative sense too. This means specifically that we must consider the way in which general historical relations mediate the production and reception of art. For it is only under such conditions of mediation that the 
reflective significance of art - its logically distinctive status as a unique form of knowledge - fully emerges. It is to this task I now turn.

\section{Part Three}

Production in all fields of art-making - indeed artifice in general - involves the following of rules. Similar considerations pertaining to methodology, rigour, the gathering of evidence, and verification procedures, also guide the pursuit of forms of knowledge in general.

Now in the case of artifice (in industrialised societies at least) the bulk of production is effected simply by following rules. The criteria of functional efficiency which determine work process and their end products, make the particular identity of the producer into something contingent. Who one is as a person; and one's particular interests are abilities may lead to one doing one job rather than another; special aptitudes, indeed, may mean that one does the job rather well; but these personality factors are only significant to the degree that they promote or are conducive to efficiency. They do not figure as a necessary element in either production or end product.

Similar considerations hold (albeit more controversially) in relation to theory or discovery in most forms of knowledge. Odd personality traits, good luck, or untoward conjunctions of circumstances, all play their role in the formulation of theory and the making of discoveries. However, this role is entirely contingent. Given any body of knowledge in the human or physical sciences, it is entirely conceivable that some person or group of people other than those who formulated the knowledge in question, could have done so. The essential features of Kant's philosophy, or Einstein's theories of Relativity, for example, could have been formulated by others - given, of course, that the historical framework and precedents which informed the formulation of such theories, had already been laid down. Likewise in the field of technological invention, someone other than James Watt could have invented the steam engine; someone other than Frank Whittle could have invented jet propulsion. 
In the case of art, in contrast, matters are much more complex. Kitsch works, and most products of mass culture are produced according to fairly distinct formulae of functional efficiency. Even here, however, the role of individual creativity is more than simply a contingent one. The hugely successful t.v. soap opera Coronation Street, for example, was devised by Tony Warren in 1960. The idea for a drama series based on northern English working-class life, of course, could easily have been devised by someone else; but the possibilities of plot and characterisation presented by his original idea - the, as it were, flesh of Coronation Street - are very much a function of Warren's idiosyncratic original formulation. In the case of 'high art', the role of individual creativity is utterly and absolutely central, and should be stated in the strongest possible terms. The key concept here is originality. It has two basic dimensions - refinement and innovation. A work which refines is one which takes up established motifs and idioms and articulates them to an unprecedented degree of excellence. The innovatory work, in contrast, is unprecedented in the way it departs from existing motifs and idioms, and introduces new ones.

Now artistic originality is unique. For the item which is original here is a sensible material particular - viewed in relation to the traditions which inform production in that medium. This means that the original artwork is internally related to the identity of its creator or ensemble of creators. No other person or group could have created it. Consider the paintings of Watteau. His oeuvre combines some traditional motifs, but in a way that both refines and - vis-a-vis his free handling of paint and emphasis on the passing moment - innovates in relation to tradition. Now it is possible that, given the right historical circumstances, someone other than Watteau could developed a similar mode of originality, but no one other than Watteau could have produced those individual works which constitute his oeuvre. Likewise with literature and music. There are eccentrics who like to dispute Shakespeare's authorship of the body of the work attributed to him. However, whilst one might in principle argue in these terms, one cannot argue that, say, the play called Hamlet could have been written by two different people entirely independently of one another. It may be that two different people could write plays reproducing the plot of Hamlet in ex- 
actly the form in which Shakespeare presents it to us, but - unless they were familiar with Shakespeare's Hamlet (i.e. simply copied it) - they could not come up with a work identical in all respects to it.

At this point it is worth considering a putative objection to this position. It holds that given some original artwork, is it not at least logically possible that entirely independently of the artist, someone else might create a work that is perceptually (construing perceptually in a broad sense) indistinguishable from it? Such a possibility may indeed be empirically unlikely to an extreme degree, but if it is at least a logical possibility, this is enough to undermine the claim that the original artwork is internally related to the unique person or ensemble responsible for its creation. In reply to this, one must insist on a clarification of the notion of 'logical possibility'. It may be that we can imagine - in loose terms - two artists coming up with the same 'original' entirely independently of one another, but fantasy (as is the case here) and logical possibility are not synonymous. Indeed, given the fact that each embodied subject necessarily occupies a portion of the spatio-temporal continuum which cannot be occupied by another such subject, the notion of a person creating an artwork using exactly the same choice of word and imagery, and exactly the same degree of pressure in applying paint to a canvas, is simply absurd. It contradicts the very notion of the finite embodied subject.

My major claim, then, is that (in contradistinction to all forms of technological production and theory and discovery in other forms of knowledge) in original art, the personality of the creator is internally related to the final product. Now earlier on I described the way in which art in general can be seen to embody an ontological increase of being for experience itself. In original art this increase is deepened precisely because of the internal relation between the identities of the artwork and its creator(s). Let me explain this. All experience is a function of what is private to the particular exbodied subject, and that subject's inherence in a shared world of things, other persons, institutions, and values. Now in the original artwork, individuality of vision is achieved through an interaction - harmonious or conflictual - with the shared world. The reciprocity of individual self and otherness which is at the basis of all experience is here thematised in the most positive 
terms as an object of perception. Self and Other are experienced as mutually enchancing in a way that draws on the totality of the senses and imagination rather than on intellectual recognition alone. Again, experience attains a kind of ontological self-songruence or possession.

There is also a crucial ethical increase of being involved here. To interact positively with one's fellow humans demands at the very least a respect for oneself and for other people. At the heart of this is a sense of mutuality - of problems, situations, and strategies shared. Now in our interactions with other people, this mutuality is generally under pressure - from, in the one direction, an excess of the abstract, and, in the other, an excess of the concrete. The abstract dimension centres on the fact that no matter how much another person tells us how he or she thinks or feels, we can never - qua finite embodied subject see the world from where the other sees it. The unfulfillable longing for such congruence constitutes, of course, the poignancy of human love. We need the fullness of the other's view of things, but it is not wholly available to us; it remains to some degree abstract. At the opposite extreme there are many occasions, when, with those who we care for, or who are of interest to us, we become preoccupied by them at existential cost to ourselves. We feel under pressure to identify with their problems, or to offer advice etc. Now (in a metaphorical sense) the great beauty of original art is the way it situates us between these two extremes vis-a-vis mutuality. On the one hand we are shown a view of the world which is necessarily tied to the person who has created it, but which is not simply a factual report of how he or she happens to think or feel about such and such a subject-matter. It is a view of things which draws - through its very structure - on thought, the senses, and feeling. We touch the creator in real and concrete rather than abstract terms. On the other hand, this is a work - a physical object that has through being finished, become causally discontinuous from the physical existence of its creator. This means that the other's vision which is embodied in the work is one which, to some degree we can enjoy on our own terms. We can recognise common interests and strategies etc., without feeling that compulsion or pressure to recognize which is part and parcel of our direct social and emotional interactions with other people. This unique 
aesthetic mode of empathy is one where mutuality - in the sense of respect for the other and respect for self is at a premium.

Let me now summarise and comment on the scope of the theory of art which I have been outlining. My basic point is that artistic originality is sui generis. Whereas in all other forms of production - be it technology or knowledge in the human and physical sciences - the personality of the producer is only contingently related to process and production, in art it plays a necessary role. It is this necessity - this depth of contact with the person - which enables the artwork to increase the being of both the producer's and recipient's experience. Now it is crucial to understand the scope of this claim. The world of human choices and actions cannot be determined with the clarity of a mechanical system of slots and grooves. Human praxis has its opaque boundary zones; and art is no exception to this. Here are some examples. First, as I noticed earlier, much art is of the kitsch or mass culture variety. This means that it is derived closely from models already laid down, on the basis of formulae bound up with functional efficiency vis-a-vis entertainment value. In other cultures, symbolically significant sensible manifolds are often produced according to models laid down by tradition for very specific ritual purposes. Now in these cases, the artwork is generally consumed purely in terms of its ostensible function. However, it may be that in comparison with other such functional artifacts, the work appears original in the senses which I described earlier. If this is so, the work will stand out in evaluative terms. It will bring about those increases of being which are distinctive to the production and experience of art. Originality, as it were, energises such potential. This is also true of the applied arts, in a complex way. If some functional artifact such as a building, or a piece of cutlery of furniture, is created in an original way (in respect of its appearance or the way it fulfils its function) then it takes on a symbolic as well as sensible presence. It declares itself as a distinctive way of fulfilling that function. It becomes a self-representational manifold.

The most important boundary zone of all occurs within what is generally accepted within western or western-influenced culture as art-practice. Hundreds of thousands of works are produced by students, amateurs and aspiring artists. Many of these simply involve a coming to 
terms with motifs and idioms already established. Some will go beyond this in the direction of genuine originality but the bulk will not. Again within the artworld, there is the boundary zone which surrounds minimal works. I mean the term 'minimal' here in the most literal sense. One could, for example, imagine a poem consisting say, of just one word - 'Decay...'. Likewise there are many minimal visual 'artworks' such as Robert Smithson's Slab which consist of one simple form - often produced in a medium according to an artist's instructions, rather than made by him or herself. In such cases, a work may be original - quite strikingly so; but they do not have an internal relation to the creator's experience. Someone else could, in principle, have devised exactly the same works. In these cases, what is at a premium is the artist's wit or intelligence. This kind of creativity is qualitatively difference from that involved in making art. However, there is obviously an ambiguous area between the two. Structurally simple works such as, say Malevich's White on White, or Black Cross, could have been produced according to specifications laid down by the creator, rather than by the creator himself. In this sort of case, matters can only be decided by debate concerning the specific example. One must decide such things as to what degree the artist's touch or choice in the articulation of particular details within the fabric of the whole are important. If key elements in the work's phenomenal fabric are left undetermined by the artist (i.e. basic instructions are issued but it is left to others to decide the exact nature of their realization), then the mode of creativity involved is distinct from that involved in the making of original art.

The whole issue addressed by my discussion comes down to this. Human beings have the capacity to make symbolically significant sensible manifolds. Within this class of artifacts, ones which are original are so in a distinctive way that cannot be explained in terms which characterise techniques of production in other spheres of artifice, or in the formulation of knowledge. We need a word to pick out this unique and irreducible human practice. And, of course, we have one - art . The concept of art has involved historically in concert with the decline of overt social function in favour of the creation of symbolically significant sensible manifolds for their own sake. 'For their own sake' is not some simple unanalysable fact - some irrational and inexplicable need 
to produce. It is rather an acknowledgment that in its absolute fusion of the symbolic and the sensuous, art yields a knowledge of the self's relation to the world and to other persons, which is unique. It is this truth which has, alas, been forgotten by many inane post-war pseudo-artists, and those blinkered academics who trail in their wake.

The concept art, then can be used with a small ' $a$ ' in a very general sense to encompass symbolically significant sensible manifolds per se. However, Art with a capital ' $\mathrm{A}$ ' is that symbolically significant manifold whose originality is internally related to the existence of its creator(s). This dimension of originality is one which changes our relation to the manifold. Rather than see it as mere decoration or as an object of functional or escapist significance, deeper levels of awareness are engaged. In enjoying the various aspects of its original formal structures, we find the reflection of essential structures in self-consciousness itself. The world of otherness echoes our own being; its foreigness is overcome. Now, of course there is no convention whereby art is explicitly 'read' in these terms. Rather the reflection of self-consciousness is grasped intuitively. Intuitive articulation is when understanding or recognition is achieved not through intellectual cognition alone, but through a complex co-ordination of concepts and sensibilia. This fullness of meaning can be 'cashed out' in purely abstract conceptual terms (as in the present analysis, and the tradition from which it stems) but to do so is to strip down and denude the experience.

Art then, is a unique form of knowledge which enhances our experiential relation to things. In its creation or reception, potentially antagonistic relations between subject and object of experience are overcome. In one sense, it would be appropriate to describe this theory as an existential definition of art. This, however, would be slightly misleading in that the theory has its origins in a tradition reaching beyond existential philosophy, and, indeed, has a significance that also outreaches it. For any account of quality in human life must link up with broader questions of the relation between an organism and its environment. In so far, therefore, as art embodies an achieved quality of experience, it is a crucial element in human ecology. It is for this reason I describe my approach as an ecological definition of art. 